\title{
Optimal Airflow Control of Laboratory Air Handling Unit (LAHU) Systems
}

\author{
Yujie Cui \\ Graduate Student \\ Energy Systems Laboratory \\ University of Nebraska
}

\author{
Mingsheng Liu Ph.D., P.E. \\ Associate Professor \\ Energy Systems Laboratory \\ University of Nebraska
}

\author{
Kirk Conger P.E. \\ Energy Projects Engineer \\ Facility Operation and Control \\ University of Nebraska
}

\begin{abstract}
An optimal airflow control method and procedure have been developed for laboratory air handling unit (LAHU) systems using linear optimization theories. The optimal airflow control minimizes the thermal energy consumption and the cost, and improves the indoor air quality. This paper presents modeling, optimization procedures and optimal airflow control sequences.
\end{abstract}

\section{INTRODUCTION}

Heating, cooling, and fan energy consumption of laboratory buildings are several times higher than in typical commercial buildings since large amounts of outside air are used. To decrease the laboratory building energy consumption, a number of energy conservation measures and new systems have been developed. Heat recovery devices decrease heating and cooling energy consumption associated with the outside air intake in large number of existing systems [Sauer and Howell, 1981; Khoury and Chang, 1988; Barker, 1994; Bard, 1994; Lacey and Smith, 1997]. The heat recovery system pre-cools the outside air during summer and pre-heats the outside air during winter. A study of air-to-air energy recovery devices indicates annual energy savings up to $23 \%$ [Sauer and Howell, 1981].

Variable Air Volume (VAV) fume hoods directly reduce the outside air requirement [Neuman and Rousseau 1986; Davis and Benjamin 1987; Boldt 1993]. The VAV fume hood maintains constant face velocity at the fume hood only. When the sash is partially closed, the airflow is proportionally reduced. The VAV fume hood can reduce the outside air intake by as much as $60 \%$ [Neuman and Rousseau 1986].

Usage Based Control (UBC) devices reduce the airflow for both the constant and VAV fume hoods [Phoenix Controls Corporation, 1999]. The UBC device decreases the face velocity of the fume hood from $0.5 \mathrm{~m} / \mathrm{s}(100 \mathrm{fpm})$ to $0.3 \mathrm{~m} / \mathrm{s}(60 \mathrm{fpm})$ when the operator is not presented in the front of the hood.
The Laboratory Air Handling Unit (LAHU) system integrates the office and laboratory sections together. It can re-circulate the office section air to the laboratory section. A study showed that the LAHU system provides better indoor air quality (IAQ) and uses up to 30\% less thermal energy than the conventional AHUs when the airflows are controlled properly [Cui and Liu, 2001].

In this paper, the optimal airflow control of LAHU system is developed using the linear optimization theories. This paper presents the system modeling, optimization procedures, and the optimal airflow control sequences.

\section{LAHU SYSTEM AND THE OBJECTIVE FUNCTION}

Figure 1 shows the schematic of the LAHU system. The objectives of the airflow optimization are to minimize the thermal energy consumption and to improve the building IAQ. The optimization parameters are the outside air intake ratios to the office and the laboratory sections. The air release ratio and the return air flow ratios to the upstream and the downstream of the laboratory cooling coil can be determined using the outside air intake ratio based on building airflow balance principals.

The primary independent variables are the outside air temperature and the enthalpy, the room air temperature and relative humidity, the total airflows to the office section and the laboratory section, and the supply air temperatures to both sections. The supply air temperature of the laboratory section is higher than the design supply air temperature of the office section since the laboratory section needs a minimum exhaust airflow, which is higher than the airflow required for thermal comfort.

The optimization takes the thermal energy savings as the first priority provided the building minimum IAQ is satisfied. If the building IAQ can be improved without decreasing the thermal energy savings, the optimal schedules maximize the benefit of IAQ. 


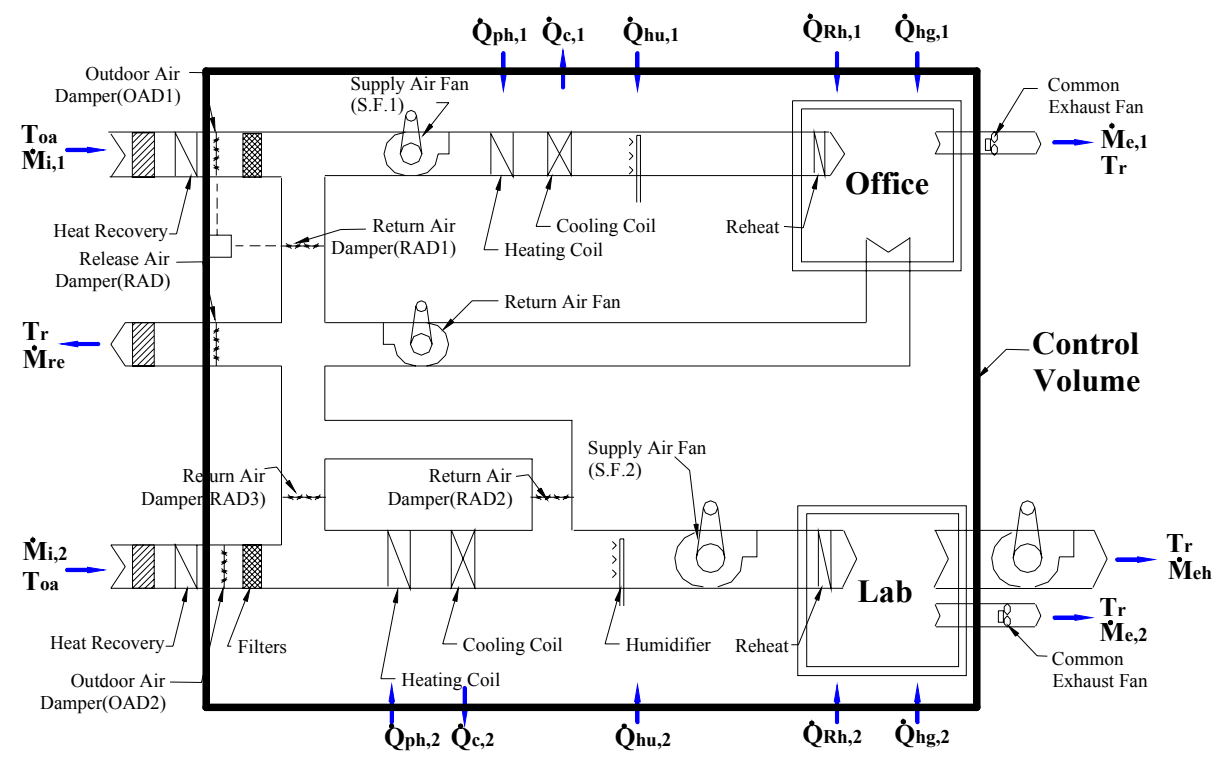

Figure 1: Schematic of LAHU systems

The objective function is set as the total thermal energy consumption (heating, cooling, reheat and humidification) of the LAHU system. Taking the entire building as the control volume, the energy balance is:

$\dot{Q}_{h}+\dot{Q}_{h u}=\dot{Q}_{c}+\dot{Q}_{r e}+\dot{Q}_{e}+\dot{Q}_{e h}-\dot{Q}_{i}+\dot{Q}_{e n v}-\dot{Q}_{h g}$

From equation (1), the total thermal energy can be expressed as

$\dot{Q}=2 \dot{Q}_{c}+\dot{Q}_{r e}+\dot{Q}_{e}+\dot{Q}_{e h}-\dot{Q}_{i}+\dot{Q}_{e n v}-\dot{Q}_{h g}$

Equation (2) shows that the total thermal energy consumption depends on the cooling consumption, the enthalpy of exhaust air, the enthalpy of release air, the enthalpy of intake air, and independent operational terms. If heat recovery devices are not present, the intake air is outside air. Otherwise, the intake air is the discharge air of the heat recovery system. In the following discussion of this paper, intake air is referred as outside air. Therefore, the equation (2) is rewritten as

$$
\dot{Q}=2 \dot{Q}_{C}+\left(\dot{M}_{e}+\dot{M}_{r e}\right) h_{r, 1}+\dot{M}_{e h} h_{r, 2}-\left(\dot{M}_{i, 1}+\dot{M}_{i, 2}\right) h_{o a}
$$

$$
+C N T
$$

Where

$$
C N T=\dot{Q}_{e n v}-\dot{Q}_{h g}
$$

For a given weather condition, $\mathrm{C}$ can be treated as a constant. When the optimal control schedules are sought, the objective function can be written as equation (4).

$$
A=2 \dot{Q}_{c}+\left(\dot{M}_{e}+\dot{M}_{r e}\right) h_{r, 1}+\dot{M}_{e h} h_{r, 2}-\left(\dot{M}_{i, 1}+\dot{M}_{i, 2}\right) h_{o a}
$$

Where

$$
\begin{aligned}
& \dot{M}_{i}=\dot{M}_{i, 1}+\dot{M}_{i, 2} \\
& \dot{Q}_{c}=\dot{Q}_{c, 1}+\dot{Q}_{c, 2}
\end{aligned}
$$

Introducing equations (5) and (6) into equation (4), and applying the LAHU system mass balance to equation (4), the objective function is deduced as

$$
\begin{aligned}
A= & 2\left(\dot{q}_{C, 1}+\dot{q}_{C, 2}\right)+\beta_{1} \varphi\left(h_{r, 1}-h_{o a}\right)+\beta_{2}(1-\varphi)\left(h_{r, 2}-h_{o a}\right) \\
& +\left(1-\beta_{2}\right)(1-\varphi)\left(h_{r, 2}-h_{r, 1}\right)
\end{aligned}
$$

Where,

$$
\begin{gathered}
\dot{q}_{C, 1}=\frac{\dot{Q}_{C, 1}}{\dot{M}_{d}} \\
\dot{q}_{C, 2}=\frac{\dot{Q}_{C, 2}}{\dot{M}_{d}} \\
\beta_{1}=\frac{\dot{M}_{i, 1}}{\dot{M}_{d, 1}} \\
\beta_{2}=\frac{\dot{M}_{i, 2}}{\dot{M}_{d, 2}} \\
\varphi=\frac{\dot{M}_{d, 1}}{\dot{M}_{d}}
\end{gathered}
$$


Equation (7) shows that when the room conditions are given, the total thermal energy decreases more than the cooling energy does. Or, the heating energy reduces as the cooling energy decreases for the LAHU. If the humidification and the heating energy have the same price, the optimal thermal energy consumption also means the optimal thermal energy cost regardless the prices of the heating and cooling energy. Therefore, the optimal solution based on Equation (7) is the optimal thermal energy cost solution as well.

The optimal sequences are developed in two steps. First, the optimal airflow control sequences are developed to satisfy room comfort and overall building airflow balance. Then, the sequences are modified to satisfy IAQ.

\section{OPTIMAL AIRFLOW CONTROL FOR THERMAL COMFORT}

Since the mechanical cooling has to be expressed by different formats for the dry and the wet coil modes, the optimal airflow control is developed for the dry coil mode and the wet coil mode separately.

\section{Optimal Air Flow Control for the Dry Coil Mode}

When the outside air dew point is lower than the room air design dew point, there is no need to remove moisture from the air stream for typical laboratory buildings. The cooling coils are assumed to be in the dry coil mode although a small amount of moisture may actually be removed from the air streams depending on the coil and chilled water conditions.

The cooling energy consumptions are expressed by Equations (13) and (14) for the office and laboratory sections.

$$
\begin{aligned}
& q_{c 1}=\left\{0, C_{p} \varphi\left[\beta_{1}\left(t_{o a}-T_{r}+\left(T_{r}-T_{c, 1}\right)\right]\right\}^{+}\right. \\
& q_{c 2}=\left\{0, C_{p}(1-\varphi)\left[\beta_{2}\left(t_{o a}-T_{r}\right)+\left(T_{r}-T_{c, 2}\right]\right\}^{+}\right.
\end{aligned}
$$

Introducing Equations (13) (14) into Equation (7), the objective function becomes:

$$
\begin{aligned}
A= & 2 C_{p} \varphi\left\{0,\left[\beta_{1}\left(t_{o a}-T_{r}\right)+\left(T_{r}-T_{c, 1}\right)\right]\right\}^{+} \\
& +2 C_{p}(1-\varphi)\left\{0,\left[\beta_{2}\left(t_{o a}-T_{r}\right)+\left(T_{r}-T_{c, 2}\right)\right]\right\}^{+} \\
& +\beta_{1} \varphi\left(h_{r, 1}-h_{o a}\right)+\beta_{2}(1-\varphi)\left(h_{r, 2}-h_{o a}\right) \\
& +\left(1-\beta_{2}\right)(1-\varphi)\left(h_{r, 2}-h_{r, 1}\right)
\end{aligned}
$$

Based on equation 15 and the room comfort requirement, the optimization equation set becomes:

$$
\begin{aligned}
A= & 2 C_{p} \varphi\left[\beta_{1}\left(t_{o a}-T_{r}\right)+\left(T_{r}-T_{c, 1}\right)\right] \\
& +2 C_{p}(1-\varphi)\left[\beta_{2}\left(t_{o a}-T_{r}\right)+\left(T_{r}-T_{c, 2}\right)\right] \\
& +\beta_{1} \varphi\left(h_{r, 1}-h_{o a}\right)+\beta_{2}(1-\varphi)\left(h_{r, 2}-h_{o a}\right) \\
& +\left(1-\beta_{2}\right)(1-\varphi)\left(h_{r, 2}-h_{r, 1}\right)
\end{aligned}
$$

Restriction conditions:

$$
\begin{aligned}
& \beta_{1}\left(t_{o a}-T_{r}\right)+\left(T_{r}-T_{c, 1}\right) \geq 0 \\
& \beta_{2}\left(t_{o a}-T_{r}\right)+\left(T_{r}-T_{c, 2}\right) \geq 0 \\
& 0 \leq \beta_{1} \leq 1 \\
& 0 \leq \beta_{1}-\zeta-\frac{1-\varphi}{\varphi}\left(1-\beta_{2}\right) \leq 1-\zeta \\
& 0 \leq \beta_{2} \leq 1 \\
& \text { where } \\
& \zeta=\frac{\dot{M}_{e}}{\dot{M}_{d, 1}}
\end{aligned}
$$

Restriction conditions (17) and (18) are generated from the normalization process. Equations (19) and (21) describe the capabilities of the economizers while equation (20) satisfies the airflow balance. The restrain conditions do not expose the requirement of the indoor air quality.

Equation (16) is a linear function of $\beta_{1}$ and $\beta_{2}$. According to the linear optimization theories [Nash and Sofer, 1996], the objective function has the minimal value within the restriction conditions, and the optimal solution must be located at the boundaries. Therefore, the restriction conditions are reduced to:

$$
\begin{aligned}
& \beta_{1}=\frac{T_{r}-T_{c, 1}}{T_{r}-t_{o a}} \\
& \beta_{2}=\frac{T_{r}-T_{c, 2}}{T_{r}-t_{o a}} \\
& \beta_{1}=1 \\
& \beta_{1}-\zeta-\left(1-\beta_{2}\right) \frac{1-\varphi}{\varphi}=0 \text { or } \\
& \beta_{1}-\zeta-\left(1-\beta_{2}\right) \frac{1-\varphi}{\varphi}=1-\zeta \\
& \beta_{2}=0 \text { or } \beta_{2}=1
\end{aligned}
$$

The optimal airflow control is a two-variable restricted linear optimization problem. The combination of any two restricted conditions could result in a possible optimal solution. Since seven restrictive conditions exist, there are 21 possible combinations. Some of the combinations result in 
only local optimal solutions, and some of them result in the same solution. Therefore, 11 possible combinations are listed below.

(a) $\beta_{1}=1, \beta_{2}=0$

(b) $\beta_{1}=1, \beta_{2}=\beta_{e c 2}$

(c) $\beta_{1}=\zeta+\frac{1-\varphi}{\varphi}, \beta_{2}=0$

(d) $\beta_{1}=\zeta, \beta_{2}=1$

(e) $\beta_{1}=\beta_{e c 1}, \beta_{2}=0$

(f) $\beta_{1}=\beta_{e c 1}, \beta_{2}=1$

(g) $\beta_{1}=1, \beta_{2}=1$

(h) $\beta_{1}=1, \beta_{2}=1-\frac{\varphi}{1-\varphi}(1-\zeta)$

(i) $\beta_{1}=\beta_{e c 1}, \beta_{2}=1-\frac{\varphi}{1-\varphi}\left(\beta_{e c 1}-\zeta\right)$

(j) $\beta_{1}=\left(1-\beta_{e c 2}\right) \frac{1-\varphi}{\varphi}+\zeta, \beta_{2}=\beta_{e c 2}$

(k) $\beta_{1}=\beta_{e c 1}, \beta_{2}=\beta_{e c 2}$

where

$$
\begin{aligned}
& \beta_{e c 1}=\frac{T_{r}-T_{c, 1}}{T_{r}-t_{o a}} \\
& \beta_{e c 2}=\frac{T_{r}-T_{c, 2}}{T_{r}-t_{o a}}
\end{aligned}
$$

The solution of any combination condition is a possible optimal solution of the objective function (16). The optimal solution can be selected based on the values of the objective function after introducing these possible solutions. If the solution of the combination condition results in the minimum value of the objective function, this set of solution is the optimal solution $\beta_{1}, \beta_{2}$.

The optimal solution can also be identified using graphic method following standard optimization procedures. The graphic analysis has been performed. The analysis shows that when the outside air temperature $\left(t_{o a}\right)$ is lower than the office section cold deck set point $\left(T_{c, 1}\right)$, combinations $(\mathrm{j})$ and $(\mathrm{k})$ provide the optimal solution. When the outside air temperature is between the office section cold deck set point and the laboratory cold deck set point $\left(T_{c, 2}\right)$, combination (b) results in the optimal solution. Combination (h) is a particular case. When the outside air temperature is higher than the laboratory section cold deck set point and lower than the room design air temperature $\left(T_{r}\right)$, combination $(\mathrm{g})$ results in the optimal solution. If the outside air temperature is higher than the room design air temperature, combination (c) results in the optimal solution. Combination (a) is a particular case.

The return air flow ratios to the upstream and downstream of laboratory cooling coil can be determined using the following correlations:

$\lambda_{u p}=1-\beta_{2}$
$\lambda_{\text {down }}=1-\lambda_{u p}-\beta_{2}$

The release air ratio $(\gamma)$ is interlinked with outside air intake ratios

$$
\gamma=\beta_{1}-\zeta-\frac{1-\varphi}{\varphi}\left(1-\beta_{2}\right)
$$

Table 1 summarizes the optimal control sequences for thermal comfort. Figures 2 presents a set of numerical results of the optimal airflow control schedules for typical laboratory buildings for dry coil mode. The results are generated based on the following assumptions: $60^{\circ} \mathrm{F}$ and $65^{\circ} \mathrm{F}$ cold deck temperatures for the office and laboratory sections, respectively. The room design air temperature and relative humidity are $75^{\circ} \mathrm{F}$ and $50 \%$. The common exhaust air flow ratio is $3 \%$.

Figure 2a shows that the system releases air to the outside within the economizer zone. Outside the economizer zone, the optimal control schedules use the minimal outside air, which equals the total exhaust air from the fume hoods and the common exhaust. Figure $2 b$ shows that the outside air intake fraction of the office section is increased to satisfy the minimum building outside air intake outside the economizer zone. If the office section airflow rate is higher than the building minimal airflow rate, the office section receives the entire minimal outside air. If the office section airflow rate is less than the building minimum outside airflow rate, the office section uses $100 \%$ outside air. The laboratory section takes in outside air to satisfy the minimum building outside air requirement. Therefore, the optimal schedules minimize both the heating energy consumption and the cooling energy consumption. The office section has a better IAQ since significant more outside air is directly introduced into the space. Figure $2 \mathrm{~d}$ shows that all return air is sent to the up stream of the cooling coil of the laboratory section. 
Table 1: Optimal Airflow Control Schedules for Thermal Comfort for Dry Coil Mode

\begin{tabular}{|c|c|c|c|c|}
\hline $\mathbf{T}_{\mathbf{0 a}}$ & $\beta_{t, 1}$ & $\beta_{t, 2}$ & $\lambda_{t, u p}$ & $\gamma_{t}$ \\
\hline$<\mathbf{T}_{\mathbf{c}, \mathbf{1}}$ & $\left\{\begin{array}{c}\left\{\left(1-\beta_{e c 2}\right) \frac{1-\varphi}{\varphi}+\zeta\right], \\
\left.\beta_{\mathrm{cc} 1}\right\}^{+}, 1\end{array}\right\}$ & $\left\{1-\frac{\varphi}{1-\varphi}\left(\beta_{t, 1}-\zeta\right), \beta_{\mathrm{ec} 2}\right\}^{+}$ & $1-\beta_{t, 2}$ & $\left\{0, \beta_{t, 1}-\zeta-\left(1-\beta_{e c 2}\right) \frac{1-\varphi}{\varphi}\right\}$ \\
\hline $\mathbf{T}_{\mathbf{c}, \mathbf{1}} \sim \mathbf{T}_{\mathbf{c}, \mathbf{2}}$ & 1 & $\left\{1-\frac{\varphi}{1-\varphi}\left(\beta_{t, 1}-\zeta\right), \beta_{\mathrm{ec} 2}\right\}^{+}$ & $1-\beta_{t, 2}$ & $\left\{0,1-\zeta-\left(1-\beta_{e c 2}\right) \frac{1-\varphi}{\varphi}\right\}^{+}$ \\
\hline $\mathbf{T}_{\mathbf{c}, \mathbf{2}} \sim \mathbf{T}_{\mathbf{r}}$ & 1 & 1 & $1-\beta_{t, 2}$ & $1-\zeta$ \\
\hline$\geq \mathbf{T}_{\mathbf{r}}$ & $\left\{1,\left(\zeta+\frac{1-\varphi}{\varphi}\right)\right\}^{-}$ & $\left\{0,1-\frac{\varphi}{1-\varphi}\left(\beta_{t, 1}-\zeta\right)\right\}^{+}$ & $1-\beta_{t, 2}$ & $\left\{0, \beta_{t, 1}-\left(\zeta+\frac{1-\varphi}{\varphi}\right)\right\}^{+}$ \\
\hline
\end{tabular}

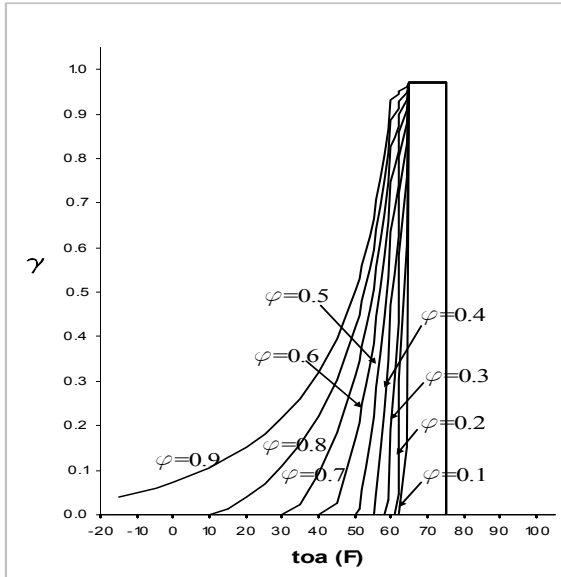

(a)

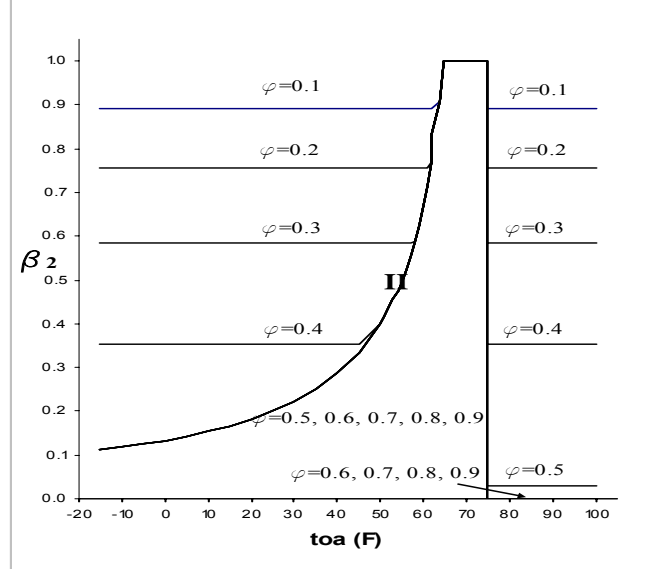

(c)

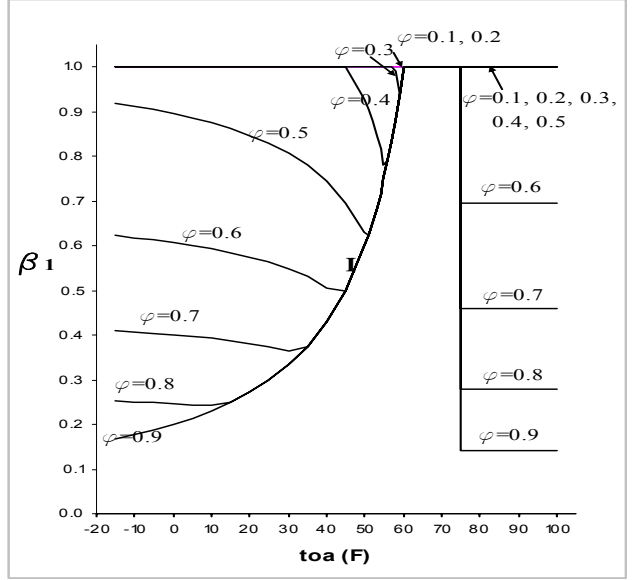

(b)

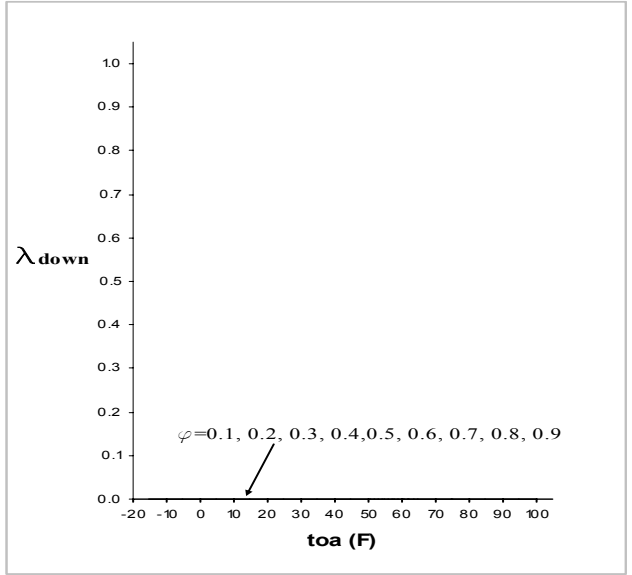

(d)

Figure 2: Graphic Optimal Control Schedules for Dry Coil Mode

\section{Optimal airflow control for wet coil}

When the outside air dew point is higher than the room design dew point, the cooling coil of office section has to remove moisture to maintain the room relative humidity level. The cooling coil of the laboratory section operates in the dry mode if it 
receives $100 \%$ air from the office section. Otherwise, it has to operate in the wet mode.

The cooling energy consumptions are calculated using Equations (33) and (34) for the office and laboratory sections

$$
\begin{aligned}
q_{c 1}= & \varphi\left[\beta_{1} h_{o a}+\left(1-\beta_{1}\right) h_{r}-h_{c, 1}\right] \\
q_{c 2}= & (1-\varphi)\left(\beta_{2}, \beta_{c r}\right)^{+}\left[\frac{\beta_{2}}{\left(\beta_{2}, \beta_{c r}\right)^{+}} h_{o a}\right. \\
& \left.+\frac{\left(0, \beta_{c r}-\beta_{2}\right)^{+}}{\left(\beta_{2}, \beta_{c r}\right)^{+}} h_{r}-h_{c, 2}\right]
\end{aligned}
$$

where

$$
\beta_{c r}=\frac{T_{S, 2}-T_{r}}{T_{C, 2}-T_{r}}
$$

Introducing Equations (33) (34) into Equation (7), the objective function becomes

$$
\begin{aligned}
A= & 2 \varphi\left[\beta_{1} h_{o a}+\left(1-\beta_{1}\right) h_{r}-h_{c, 1}\right]+2(1-\varphi)\left(\beta_{2}, \beta_{c r}\right)^{+} \\
& {\left[\frac{\beta_{2}}{\left(\beta_{2}, \beta_{c r}\right)^{+}} h_{o a}+\frac{\left(0, \beta_{c r}-\beta_{2}\right)^{+}}{\left(\beta_{2}, \beta_{c r}\right)^{+}} h_{r}-h_{c, 2}\right] } \\
& +\beta_{1} \varphi\left(h_{r}-h_{o a}\right)+\beta_{2}(1-\varphi)\left(h_{r, 2}-h_{o a}\right) \\
& +\left(1-\beta_{2}\right)(1-\varphi)\left(h_{r, 2}-h_{r}\right)
\end{aligned}
$$

Following the same procedure of the dry coil, the optimization is described by the following equation set:

$$
\begin{aligned}
A= & 2 \varphi\left[\beta_{1}\left(h_{o a}-h_{r}\right)+\left(h_{r}-h_{c, 1}\right)\right] \\
& +2(1-\varphi)\left[\beta_{2}\left(h_{o a}-h_{r}\right)+\beta_{c r}\left(h_{r}-h_{c, 2}\right)\right] \\
& +\beta_{1} \varphi\left(h_{r}-h_{o a}\right)+\beta_{2}(1-\varphi)\left(h_{r, 2}-h_{o a}\right) \\
& +\left(1-\beta_{2}\right)(1-\varphi)\left(h_{r, 2}-h_{r}\right)
\end{aligned}
$$

\section{Restricted Conditions}

$$
\begin{aligned}
& \beta_{2}=\beta_{c r} \\
& \beta_{1}=1 \\
& \beta_{1}-\zeta-\left(1-\beta_{2}\right) \frac{1-\varphi}{\varphi}=0 \text { or } \beta_{1}-\zeta-\left(1-\beta_{2}\right) \frac{1-\varphi}{\varphi}=1-\zeta \\
& \beta_{2}=0 \text { or } \beta_{2}=1
\end{aligned}
$$

optimization problem. Any combination of the two boundary conditions can potentially result in the optimal solution of $\beta_{1}$ and $\beta_{2}$. Fifteen total combinations are possible. Seven combinations are listed below since they cover all possible optimal solutions.
(a) $\beta_{1}=1, \beta_{2}=1-\frac{\varphi}{1-\varphi}(1-\zeta)$
(b) $\beta_{1}=\left(1-\beta_{c r}\right) \frac{1-\varphi}{\varphi}+\zeta, \beta_{2}=1-\frac{\varphi}{1-\varphi}\left(\beta_{1}-\zeta\right)$
(c) $\beta_{1}=1, \beta_{2}=\beta_{c r}$
(d) $\beta_{1}=1, \beta_{2}=0$
(e) $\beta_{1}=1, \beta_{2}=1$
(f) $\beta_{1}=\frac{1-\varphi}{\varphi}+\zeta, \beta_{2}=0$
(g) $\beta_{1}=\zeta, \beta_{2}=1$

The optimal solution can be obtained by selecting the minimum objective value as stated for the dry coil. Analysis has been conducted to select the optimal solution under different outside air conditions.

The analysis shows that when the outside air enthalpy $\left(h_{o a}\right)$ is lower than the room air design enthalpy $\left(h_{r}\right)$, combination (c) results in the optimal solution. Combination (a) is a particular case. If the outside air enthalpy is higher than the room air design enthalpy, combination (f) results in the optimal solution. Combination (a) is a particular case. Table 3 summarizes the optimal air flow control schedules for optimal thermal comfort for wet coil mode.

Figures 3 presents a set of numerical results of the optimal airflow control schedules for typical laboratory buildings under the wet coil operation. The simulation assumes $55^{\circ} \mathrm{F}$ cold deck set point. The room design air temperature and relative humidity are $75^{\circ} \mathrm{F}$ and $50 \%$. The common exhaust ratio is $3 \%$.

This is a two-variable restricted linear

Table 3: Optimal Air Flow Control Schedules for Thermal Comfort for Wet Coil Mode

\begin{tabular}{|c|c|c|c|c|c|}
\hline $\mathbf{h}_{\mathbf{0 a}}$ & $\beta_{t, 1}$ & $\beta_{t, 2}$ & $\lambda_{t, u p}$ & $\lambda_{t, d o w n}$ & $\gamma_{t}$ \\
\hline$\leq \mathbf{h}_{\mathbf{r}}$ & 1 & $\left\{\beta_{c r}, 1-\frac{\varphi}{1-\varphi}(1-\zeta)\right\}^{+}$ & 0 & $1-\beta_{t, 2}$ & $\left\{\left[1-\left(1-\beta_{c r}\right) \frac{1-\varphi}{\varphi}-\zeta\right], 0\right\}^{+}$ \\
\hline$>\mathbf{h}_{\mathbf{r}}$ & $\left\{\left(\frac{1-\varphi}{\varphi}+\zeta\right), 1\right\}^{-}$ & $\left\{0,1-\frac{\varphi}{1-\varphi}(1-\zeta)\right\}^{+}$ & $\left\{0, \beta_{c r}-\beta_{t, 2}\right\}^{+}$ & $1-\beta_{t, 2}-\lambda_{u p}$ & $\left\{0, \beta_{t, 1}-\left(\zeta+\frac{1-\varphi}{\varphi}\right)\right\}^{+}$ \\
\hline
\end{tabular}




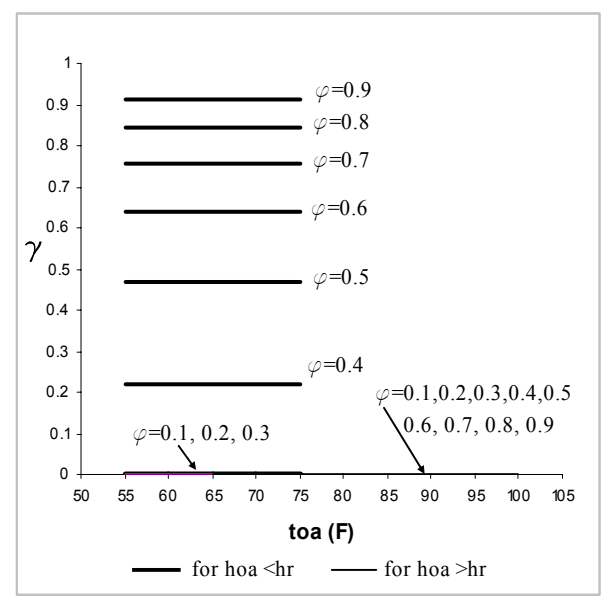

(a)

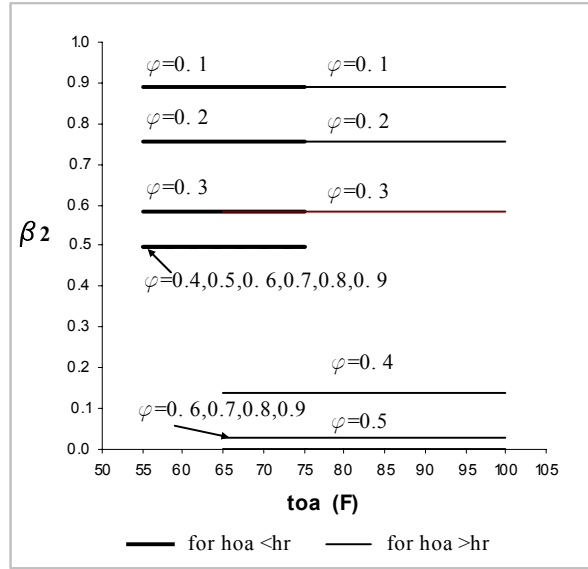

(c)

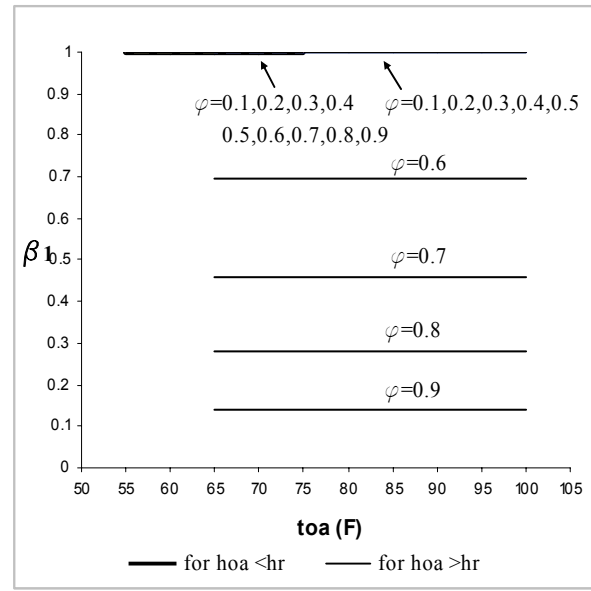

(b)

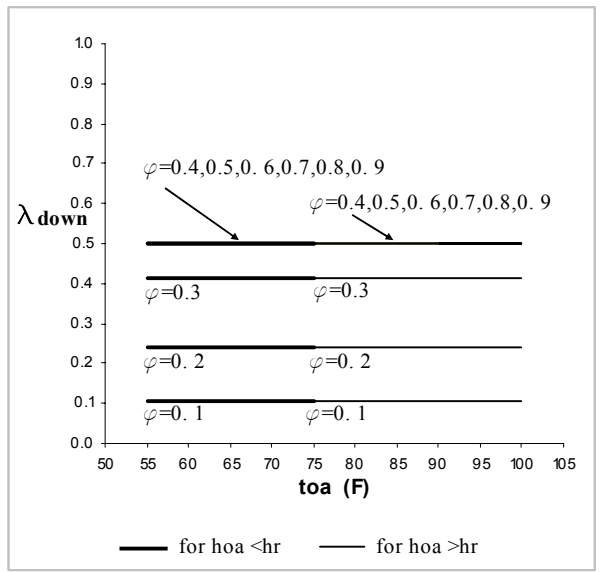

(d)

Figure 3: Graphic Optimal Control Schedules for Wet Coil Mode

When the outside air enthalpy is higher than the room design air enthalpy, the release airflow equals zero (Figure 3a). The minimum outside air intake is used. If the office section airflow is less than the building minimal outside airflow, the office section uses $100 \%$ outside air (Figure 3 b). The laboratory section takes in additional outside air to satisfy the building minimal outside air requirement (Figure 3c). If the office section airflow is higher than the building minimum airflow intake, the office section receives the entire minimum outside air directly.

When the outside air enthalpy is less than the room air enthalpy, office section uses $100 \%$ outside air (Figure 3b). If the office airflow rate is less than half of the laboratory section airflow rate, the entire return air is sent to the downstream of the cooling coil. The laboratory section takes in extra outside air to satisfy the building minimum outside air intake. If the office airflow rate is higher than half of the laboratory airflow rate, the laboratory section takes $50 \%$ outside air directly and cools it down to $55^{\circ} \mathrm{F}$, and takes other $50 \%$ return air at the downstream of the cooling coil. The mixed air temperature of these two air streams equals the deck set-point. The optimal control schedules minimize the cooling energy consumption by using the minimum outside air intake. Since the office section either receives $100 \%$ outside air, or the entire building outside air requirement, the indoor air quality of the office section is improved 


\section{OPTIMAL AIRFLOW CONTROL FOR IAQ}

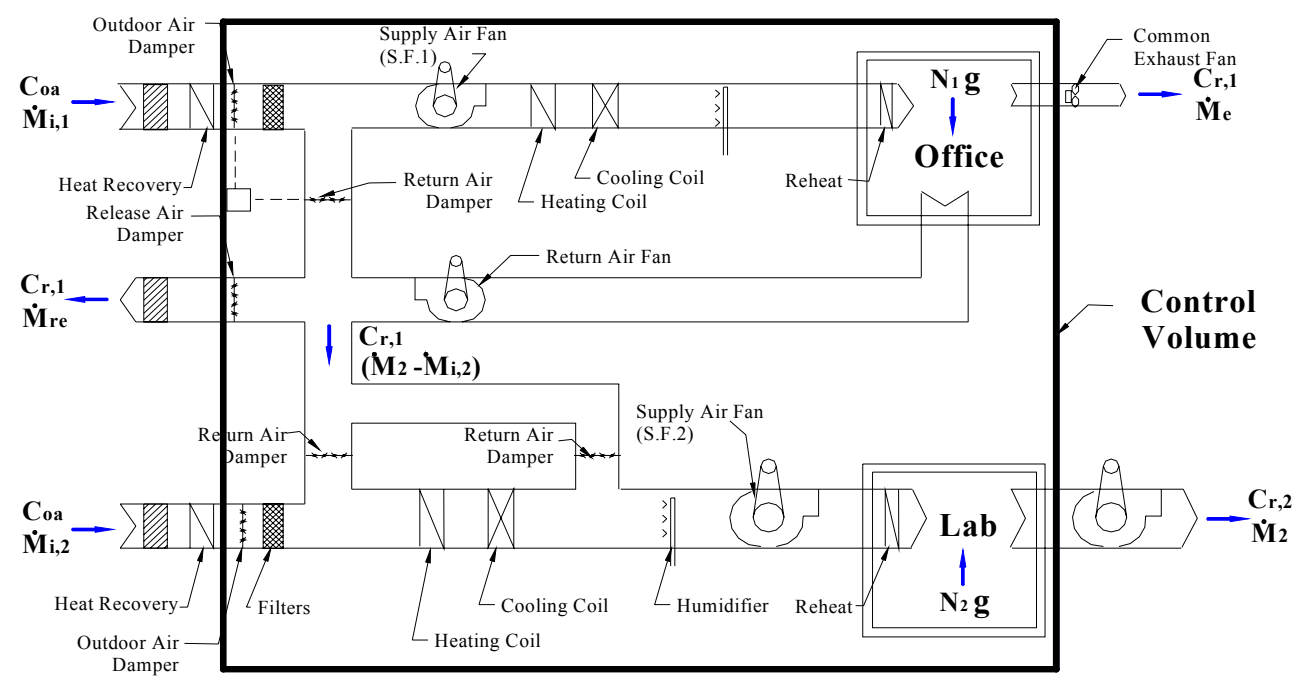

Figure 4: Schematic of LAHU System Pollution Balance

The IAQ is evaluated using the concentrations of $\mathrm{CO}_{2}$ in this paper. The minimum outside air intake is defined as the minimum IAQ. When the office section is treated separately, the minimum IAQ outside air intake fraction can be determined using equations (39) according to $\mathrm{CO}_{2}$ generation and concentration set point, and the total airflow rate.

$$
\beta_{I A Q, 1}=\frac{N_{1} g}{\left(C_{s t}-C_{o a}\right) \dot{M}_{d, 1}}
$$

The LAHU integrates the office and the laboratory sections together. The minimum IAQ outside air intake of the laboratory section can be deduced by applying pollution balance over the entire building and the office section.

$$
\begin{aligned}
& N_{1} g+N_{c} g+\left(\dot{M}_{i, 1}+\dot{M}_{i, 2}\right) C_{o a}=\left(\dot{M}_{e}+\dot{M}_{r e}\right) C_{r, 1}+\dot{M}_{d, 2} C_{r, 2} \\
& N_{1} g+\beta_{1} \dot{M}_{d, 1} C_{o a}=\beta_{1} \dot{M}_{d, 1} C_{r, 1}
\end{aligned}
$$

Combining the equations (39), (40) and (41), the minimum IAQ outside air intake of the laboratory section is expressed:

$$
\beta_{I A Q, 2}=\left(1-\frac{\beta_{1}\left(1-\beta_{I A Q, 2}^{\prime}\right)}{\beta_{I A Q, 1}}, 0\right)^{+}
$$

where

$$
\beta_{I A Q, 2}^{\prime}=\frac{N_{2} g}{\left(C_{s t}-C_{o a}\right) \dot{M}_{d, 2}}
$$

If both the office and laboratory optimal thermal outside air intakes are higher than the minimum IAQ outside air intakes, the optimal outside air intakes are the optimal thermal outside air intakes. If the office section thermal outside air intake ratio is lower than the minimum IAQ outside air intake, the minimum IAQ outside air intake is the optimal outside air intake. If the laboratory section optimal thermal outside air intake is lower than its minimum IAQ outside air intake, the optimal outside air intakes shall be determined by outside air condition.

When the outside air temperature is lower than the office section cold deck set point for dry coil mode, the optimal schedules should make the entire system take in the minimum outside air to meet IAQ without simultaneous heating and cooling. The optimal outside air intake is the higher value of $\beta_{I A Q, 1}$ and $\beta_{e c 1}$ for the office section. The laboratory section optimal outside air intake is the minimum IAQ outside air intake.

When outside air temperature is between the office section and the laboratory section cold deck set point for dry coil mode, or outside enthalpy is lower than room enthalpy for wet coil mode, optimal office section optimal outside air intake keeps the optimal thermal outside air intake $100 \%$. The laboratory section optimal outside air intake is revised to minimum IAQ outside air intake.

When the outside air temperature is higher than the room air temperature for dry coil mode or outside air enthalpy is higher than room enthalpy for the wet coil mode, the optimal outside air intake equals the minimum IAQ outside air intakes for both the office section and laboratory sections. The reason is that both sections need mechanical cooling, and the less outside air intake, the more energy-efficient under this weather condition. 
Table 3: LAHU Systems Optimal Air Flow Control Schedules

\begin{tabular}{|c|c|c|c|c|c|c|}
\hline \multirow{2}{*}{$\begin{array}{l}\text { Coil } \\
\text { Mode }\end{array}$} & \multirow{2}{*}{$\begin{array}{l}\text { Outside Air } \\
\text { Condition }\end{array}$} & \multicolumn{2}{|c|}{$\beta_{1}$} & \multicolumn{2}{|c|}{$\beta_{2}$} & \multirow[t]{2}{*}{$\lambda$ up } \\
\hline & & $\beta_{t, 2} \geq \beta_{I A Q, 2}$ & $\beta_{t, 2}<\beta_{I A Q, 2}$ & $\beta_{t, 2} \geq \beta_{I A Q, 2}$ & $\beta_{t, 2}<\beta_{I A Q, 2}$ & \\
\hline \multirow{4}{*}{$\begin{array}{l}\text { Dry } \\
\text { Coil }\end{array}$} & $\left(t_{0 a}\right)<T_{c, 1}$ & $\left\{\begin{array}{r}\left\{\left[\left(1-\beta_{e c 2}\right) \frac{1-\varphi}{\varphi}+\zeta\right]\right. \\
\left.\beta_{\mathrm{ec} 1}, \beta_{\mathrm{IAQ}, 1^{+}}\right\}^{+}, 1\end{array}\right.$ & $\left(\beta_{I A Q, 1}, \beta_{e c 1}\right)^{+}$ & $\left\{1-\frac{\varphi}{1-\varphi}\left(\beta_{1}-\zeta\right), \beta_{\mathrm{ec}}\right.$ & $\beta_{I A Q, 2}$ & $1-\beta_{2}$ \\
\hline & $\begin{array}{l}\mathbf{t}_{\mathrm{oa}}= \\
\mathbf{T}_{\mathrm{c}, 1} \sim \mathbf{T}_{\mathrm{c}, 2}\end{array}$ & 1 & 1 & $\left\{1-\frac{\varphi}{1-\varphi}\left(\beta_{1}-\zeta\right), \beta_{\mathrm{ec}}\right.$ & $\beta_{I A Q, 2}$ & $1-\beta_{2}$ \\
\hline & $\begin{array}{l}\mathbf{t}_{\mathbf{0 a}}= \\
\mathbf{T c}_{, 2} \sim \mathbf{T}_{\mathbf{r}}\end{array}$ & 1 & 1 & 1 & 1 & $1-\beta_{2}$ \\
\hline & $t_{0 a} \geq T_{r}$ & $\left\{1,\left(\zeta+\frac{1-\varphi}{\varphi}, \beta_{I A Q, 1}\right)^{+}\right\}$ & $\beta_{I A Q, 1}$ & $\left\{0,1-\frac{\varphi}{1-\varphi}\left(\beta_{1}-\zeta\right)\right.$ & $\beta_{I A Q, 2}^{\prime}$ & $1-\beta_{2}$ \\
\hline \multirow{2}{*}{$\begin{array}{l}\text { Wet } \\
\text { Coil }\end{array}$} & $h_{0 a} \leq h_{r}$ & 1 & 1 & $\left\{\beta_{c r}, 1-\frac{\varphi}{1-\varphi}(1-\zeta)\right.$ & $\beta_{I A Q, 2}$ & 0 \\
\hline & $h_{0 a}>h_{r}$ & $\left\{1,\left(\zeta+\frac{1-\varphi}{\varphi}, \beta_{I A Q, 1}\right)^{+}\right\}$ & $\beta_{I A Q, 1}$ & $\left\{0,1-\frac{\varphi}{1-\varphi}\left(\beta_{1}-\zeta\right)\right.$ & $\beta_{I A Q, 2}^{\prime}$ & $\left\{0, \beta_{c r}-\beta_{2}\right\}$ \\
\hline
\end{tabular}

Table 3 summarizes the general LAHU system optimal outside air flow control schedules. The optimal outside airflow rates depend on the minimum outside airflow requirements of office and the laboratory sections, the total airflow rates, the outside air conditions, and supply air temperature set points. The outside air and supply air conditions can be measured directly. The minimum outside air intake requirement can be measured or predicted using the design information. The optimal outside airflow can be calculated using the schedules presented in table 3 based on these measured parameters. The optimal outside air intake ratios may be implemented using different approaches. The implementation will be discussed in another paper.

\section{CONCLUSIONS}

The optimal airflow control schedules of LAHU system are developed using the linear optimization theories. Outside the economizer zone, the optimal airflow control schedules use the minimum outside air intake. The office section either receives $100 \%$ outside air or the entire building minimum outside air requirement. Inside of economizer zone, the LAHU fully take advantages of free cooling. The optimal airflow control provides the best indoor air quality while consume the least thermal energy.

The optimal airflow control can be implemented easily in programmable controllers since the optimal airflow set points are expressed using analytical equations.

\section{NOMENCLATURE}

$\begin{array}{ll}A & =\text { Objective function } \\ C & =\text { Pollution concentration rate (parts/lbm) } \\ C N T & =\text { Constant } \\ C_{p} & =\text { Specific heat for air }(\mathrm{Btu} / \mathrm{lbm} \cdot \mathrm{F}) \\ g & =\text { Pollution generation rate }(\mathrm{parts} / \mathrm{lbm}) \\ h & =\text { Air enthalpy }(\mathrm{Btu} / \mathrm{lbm}) \\ \dot{M} & =\text { Mass flow rate }(\mathrm{lbm} / \mathrm{h}) \\ N & =\text { Occupancy number }(\text { person }) \\ \dot{Q} & =\text { Total air thermal energy consumption } \\ \dot{q} & \quad \text { (Btu/h) } \\ & =\text { Air thermal energy consumption per unit } \\ T & =\text { Given or design air temperature }(\mathrm{F}) \\ t & =\text { Air temperature }(\mathrm{F}) \\ \beta & =\text { Outside air intake ratio } \\ \gamma & =\text { Office section exhaust air ratio } \\ \varphi & =\text { Ratio of office section air flow rate to total }\end{array}$
air flow rate

\section{Superscripts}

$\begin{array}{ll}+ & =\text { Maximum } \\ * & =\text { Minimum } \\ * & =\text { Optimal for thermal comfort }\end{array}$




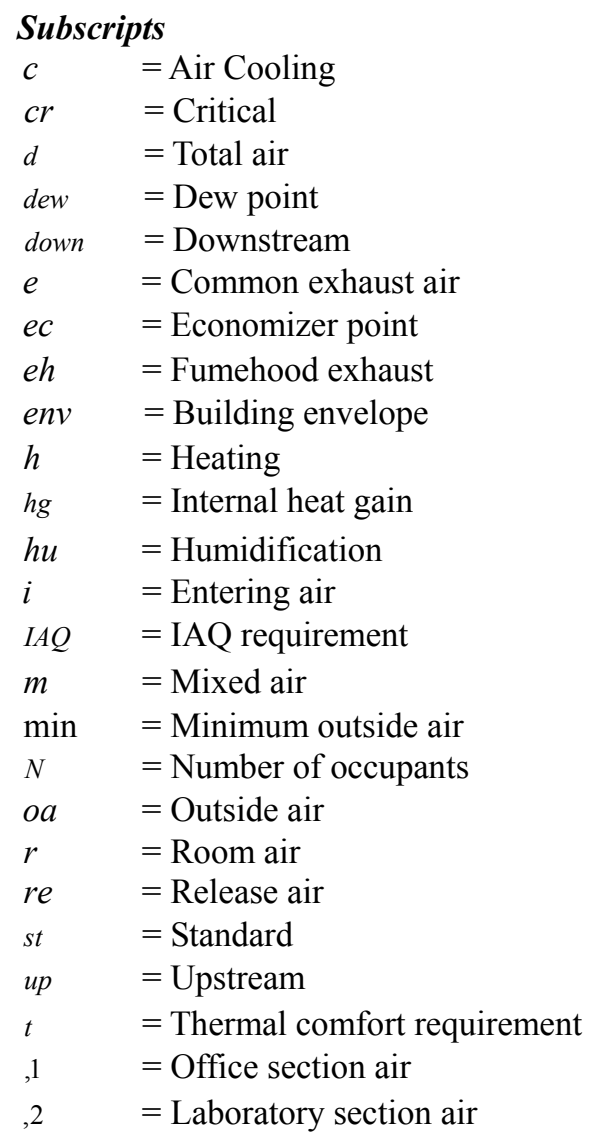

\section{REFERENCE}

Bard, E. M. 1994. "Energy Efficient HAVC System Features Thermal Storage and Heat Recovery." ASHRAE Journal V. 36.

Bard, E. M. 1995. "Laboratory Integrates VAV Fume Hood Controls With Central Building Automation System.” ASHRAE Journal V. 37.

Barker, P. L. 1994. "Biomedical Laboratory Use VAV Fume Hoods and Heat Recovery to Save Costs." ASHRAE Journal V. 36.

Boldt, Jeffrey G.. 1993. "Separate HVAC systems maximize energy efficiency." ASHRAE Journal V. 35.

Cui, Yujie and Liu, Mingsheng. 2001. "Laboratory Air handling Unit System." Proceedings of International Conference for Enhanced Building Operation.

Davis, S. J. and R. Benjamin. 1987. "VAV with Fume Hood Exhaust System." Heating/piping/Air Conditioning V. 59.
Khoury, G.A. and Chang, S. N. 1988. "An Investigation of Chemical Fume Hood Exhaust Air in a Heat Recovery Unit." American Industrial Hygiene Association Journal V. 49.

Lacey, D. Randall and Smith, Darin C. "Innovative Ventilation System for Animal Anatomy Laboratory." ASHRAE Journal V. 39.

Nash, Stephen G. and Sofer, Ariela. 1996. "Linear and Nonlinear Programming."

Neuman, V.A. and W.H. Rousseau. 1986. "VAV for Laboratory Hoods — Design and Costs." ASHRAE Transactions Vol. 92, Part 1A.

Phoenix Controls Corporation, 1999.

Sauer, H J. and Howell, R H. 1981. "Promise and Potential of Air-to-Air Recovery Systems." ASHRAE Transaction V. 87, Part 1 . 